\title{
Lenalidomide/Low-dose Dexamethasone Regimen
}

National Cancer Institute

\section{Source}

National Cancer Institute. Lenalidomide/Low-dose Dexamethasone Regimen. NCI

Thesaurus. Code C136274.

A chemotherapy regimen consisting of lenalidomide and low-dose dexamethasone that is used for the treatment of plasma cell myeloma. 